\title{
Feeding behaviour of Bactericera cockerelli (Šulc) (Hemiptera: Psylloidea: Triozidae) changes when infected with Candidatus Liberibacter solanacearum
}

\author{
Isabel Valenzuela ${ }^{1}$ - Manoharie Sandanayaka ${ }^{2} \cdot$ Kevin S. Powell ${ }^{3} \cdot$ Sorn Norng ${ }^{1} \cdot$ Jessica Vereijssen ${ }^{4}$
}

Received: 22 July 2019 / Accepted: 17 August 2020 / Published online: 29 August 2020

(c) The Author(s) 2020

\begin{abstract}
Pathogens which need a vector for their transmission can alter the vectors' behaviour to favour their spread. We used the electrical penetration graph technique to investigate this hypothesis by using the tomato potato psyllid Bactericera cockerelli infected or not with the plant pathogen Candidatus Liberibacter solanacearum (CLso) on African boxthorn and tomato. Probing was not affected by the host type but there was a significant effect on probing due to the infection status of the psyllid. More psyllids carried out probing activities in the sieve elements when infected with CLso, and more probing activities were observed from CLso-infected psyllids by comparison to the non-infected groups. Specifically, significant increases in salivation, phloem ingestion and number of probes, before and after reaching the sieve elements, were noticed in the infected groups. Furthermore, time elapsed to reach the sieve elements was significantly shortened by $2 \mathrm{~h}$ in the infected group. Remaining probing activities in xylem tissues were not different between all psyllid groups. The observed changes in feeding behaviour by pathogen-infected psyllids may well ensure further spread of the pathogen as greater salivation has the potential to increase transmission, highlighting at the same time the important role that crop and non-crop hosts play in disease epidemiology.
\end{abstract}

Keywords Insect-plant-pathogen interactions $\cdot$ Probing $\cdot$ African boxthorn $\cdot$ Tomato

\section{Introduction}

Plant pathogenic "Candidatus Liberibacter" species are phloem-restricted bacteria that depend on psyllids for their transmission (Haapalainen 2014). Psyllids acquire the bacteria during ingestion of phloem sap from infected plants and transmit it during salivation in the sieve elements (Cen et al. 2012; Sandanayaka et al. 2014). This close relationship

Handling Editor: Yulin Gao.

Isabel Valenzuela

Isabel.valenzuela-gonzalez@agriculture.vic.gov.au

1 Agriculture Victoria, AgriBio, Centre for AgriBioscience, Bundoora, VIC 3083, Australia

2 The New Zealand Institute for Plant \& Food Research Limited, Private Bag 92169, Auckland, New Zealand

3 Sugar Research Australia, PO Box 122, Gordonvale, QLD 4865, Australia

4 The New Zealand Institute for Plant \& Food Research Limited, Private Bag 4704, Christchurch, New Zealand between the insect, the host plant and the plant pathogen has important effects on the vector, particularly on its behaviour and fitness, reviewed in (Sugio et al. 2015; Tamborindeguy et al. 2017; Eigenbrode et al. 2018). For instance, the Asian citrus psyllid Diaphorina citri Kuwayama and the tomato potato psyllid Bactericera cockerelli (Šulc) preferred to land on pathogen-infected plants by comparison to non-infected plants (Wu et al. 2015; Mas et al. 2014) whilst fecundity and nymphal survival decreased significantly in pathogen-infected B. cockerelli (Nachappa et al. 2012). Feeding changes were studied when pathogenic bacteria were present in the plant (Cen et al. 2012) or in the psyllid (Sandanayaka et al. 2014; Antolinez et al. 2017a, b; Killiny et al. 2017), with results showing an increase or decrease in feeding related activities, i.e. salivation and phloem and xylem ingestion. It is assumed that these changes promote the spread of the pathogen by increasing contact between the host plant, the insect and the plant pathogen.

This idea fits with the "host manipulation hypothesis", which focused on animal parasite systems and postulates that parasites can alter their host behaviour to promote their 
spread (Poulin 2010). This idea is also relevant to plant pathogens that depend on insect vectors for their spread including phloem-restricted plant pathogenic bacteria that need a phloem feeding vector for its transmission and acquisition (Haapalainen 2014). This hypothesis depends on two conditions being met which are that the vector's altered behaviour benefits the pathogen and that the altered behaviour is controlled by the pathogen (Mauck et al. 2019; Bernardo and Singer 2017). The molecular pathways by which pathogens induce phenotypic changes in the vectors are not fully understood or known for all pathosystems, but work on bacteria and viruses is suggesting that pathogen specific proteins can alter vector and host plant cell morphology, signalling pathways, immune response and cell physiology (Tamborindeguy et al. 2017; Sackton 2018; Mauck et al. 2019; Sugio et al. 2015; Bernardo and Singer 2017). The rise of functional genomic and phenomic technologies has allowed this field of research to expand rapidly in recent times, given their potential for characterizing molecules which are present in the vector (or the host plant) at any point in time of the infection cycle. More studies, however, have been carried out in virus/vector pathosystems than bacteria/vector pathosystems despite these being important vectors of disease.

Bactericera cockerelli is a major pest of Solanaceous crops in North and Central America (CABI 2018) and New Zealand (Teulon et al. 2009). This psyllid is the vector of Candidatus Liberibacter solanacearum (CLso), a bacterial plant pathogen that causes Zebra chip disease in potato (Secor et al. 2009) and an unnamed disease in tomatoes (Hansen et al. 2008; Sengoda et al. 2013). In February 2017, B. cockerelli was detected in Perth, Western Australia (AIQ 2017) and was declared not apt for eradication due to its widespread distribution around Perth. To date, there are no records of the species having dispersed to the eastern States or of the presence of the pathogen CLso in mainland Australia. Nevertheless, the presence of the insect in Western Australia increases the risk of disease which is known to affect yield and quality of potatoes (Buchman et al. 2011).

In New Zealand, B. cockerelli and Zebra chip disease spread to every potato cultivation region (Teulon et al. 2009) soon after its initial detection in the Auckland region in 2006 (Gill 2006). This rapid spread of the pathogen prompted a large-scale research effort designed to understand the biology of the pest and the pathogen so to minimize impacts on the relevant horticultural industries e.g. potato, taewa, tomato, tamarillo, chilli and capsicum. Many aspects were studied which included psyllid host plant surveys (cultivated and non-cultivated plants) (Dohmen-Vereijssen et al. 2016), CLso survey (Vereijssen et al. 2015), B. cockerelli life history on cultivated and non-cultivated plants (DohmenVereijssen et al. 2016), and feeding studies (Sandanayaka et al. 2017). Host plant surveys identified many non-cultivated Solanaceous plants that served as "true hosts", as eggs, nymphs and adults were detected, including African boxthorn (Lycium ferocissimum Miers), Jerusalem cherry (Solanum pseudocapsicum L.) and common thorn-apple (Datura stramonium L.) (Dohmen-Vereijssen et al. 2016). These hosts are also found in Australia and have the potential to become reservoirs of $B$. cockerelli outside the cropping areas and growing season as shown in the New Zealand field surveys. The pathogen CLso, was also detected in fieldcollected Jerusalem cherry and common thorn-apple (Vereijssen et al. 2015), but was not found in African boxthorn. There was, however, a successful transmission of CLso to African boxthorn plants in laboratory conditions using infected psyllids (Dohmen-Vereijssen et al. 2016).

Many studies have investigated the effects that plant pathogens have on their vectors; particularly on the traits that favour pathogen spread such as host choice (Mauck et al. 2010), dispersal and sexual behaviours (Martini et al. 2015), production of wing forms (Shi et al. 2016), life history traits (Mann et al. 2008) and feeding (Lei et al. 2016), reviewed in (Fereres and Moreno 2009; Bosque-Pérez and Eigenbrode 2011; Sugio et al. 2015; Han et al. 2015; Tamborindeguy et al. 2017; Eigenbrode et al. 2018). The electrical penetration graph (EPG) technique was developed to understand Hemipteran feeding by measuring small changes in electrical resistance associated to specific probing activities of the stylet tip position in plant tissue (McLean and Kinsey 1964; Tjallingii 1978; Walker 2000). This technique is increasingly being used for understanding the effects that plant pathogens have on their vectors' feeding behaviour as it allows for real-time observations of the stylet tip position in plant tissue helping researchers to make inferences about specific feeding changes, and pathogen movements from the plant to the insect and vice versa. This is the case for many psyllids that have become important pests in recent times due to their ability to transmit pathogenic Candidatus Liberibacter species in Rutaceae (Halbert and Manjunath 2004), Solanaceae (Butler and Trumble 2012), Apiaceae (Alfaro-Fernández et al. 2012), and Rosaceae (Thébaud et al. 2009).

Our study aimed at investigating the feeding behaviour of infected and non-infected $B$. cockerelli, by testing the hypothesis that insect feeding behaviour is altered by the presence of a pathogen. This idea has been tested on B. cockerelli feeding on tomato (Sandanayaka et al. 2014), B. trigonica feeding on carrots (Antolinez et al. 2017a, b) and D. citri feeding on Citrus sp. (Killiny et al. 2017). This idea, however, has not been tested for $B$. cockerelli feeding on the perennial non-crop host African boxthorn. Yet, this host may be playing an important role in the epidemiology of the disease in New Zealand. Potato crops in New Zealand, which are frequently infected with CLso, are in some areas surrounded by African boxthorn plants which are used as wind protective hedges or occur in rived beds and sea dunes. CLso has not been detected in field African boxthorn 
plants but has been successfully transmitted in laboratory conditions. In order to understand better the behaviour of infected psyllids when exposed to this host and to validate laboratory experiments of CLso transmission to African boxthorn plants, we used the direct current electrical penetration graph (DC-EPG) technique to investigate changes in probing behaviour from CLso-infected and non-infected B. cockerelli on two host plant species; the weed African boxthorn (also widely present in Australia) and the crop plant tomato (S. lycopersicum L.). We used tomato plants alongside African boxthorn plants as control plants given the availability of published EPG results on this host. A better understanding of B. cockerelli and CLso interactions with their crop and non-crop hosts will improve pest and disease management strategies in New Zealand and biosecurity readiness in Australia.

\section{Material and methods}

\section{Insects and plants}

The CLso-free B. cockerelli colony was established from the adults and nymphs originally collected from greenhouse tomatoes in Auckland and were reared on CLso-free capsicum plants (Capsicum annиum L. cv. "Giant Bell"). Adults and nymphs of CLso-infected TPP were originally collected from CLso-infected potato plants in 2009 in Pukekohe, Auckland, and reared on CLso-symptomatic tomato plants (S. lycopersicum L. cv. "Moneymaker"). Uninfected (CLso-free) and CLso-infected colonies of $B$. cockerelli were maintained in separate glasshouses at Plant \& Food Research (PFR) Mt Albert, Auckland, New Zealand. Both colonies were maintained in steel frame cages $(50 \times 50 \times 50 \mathrm{~cm})$ covered with fine netting, containing 4 plants. The plant material provided to the CLso-free colony was tested for CLso before being used in the colonies, any positive or inconsistent reading resulted in the plants being discarded. The colonies were maintained at $25^{\circ} \mathrm{C}, 16: 8 \mathrm{~L}: \mathrm{D}$, $40-50 \%$ RH. Ten randomly selected B. cockerelli per cage (4 cages for each colony type) were tested for CLso every 5-10 weeks, first following the multiplex PCR protocol by Liefting et al. (2008) and later using the DNA extraction and qPCR protocols developed by Beard and Scott (2013). The non-infected colonies have tested $100 \%$ negative since 2006, and the infected colonies have tested $100 \%$ positive for CLso since 2010. All insects used in the EPG recordings were young females which had recently moulted to the adult stage (we selected yellow coloured psyllids indicating their recent moult to adulthood), and consequently unlikely to be gravid and oviposit.

Test plants, one-month old tomato cv. "Moneymaker" and four months old African boxthorn, were grown in glasshouse conditions at $24 \pm 1{ }^{\circ} \mathrm{C}$ and L15:D9 photoperiod and used for EPG recordings. Tomato cv. "Moneymaker" was obtained as seed stock (Yates) and was chosen for its commercial use in New Zealand and Australia, whereas African boxthorn seeds were collected from the field in 2015 in New Zealand. Tomato seeds were placed in a germinating tray containing potting mix and the soil was watered every $2-3$ days. African boxthorn seeds were soaked in water for $24 \mathrm{~h}$ before being placed in potting mix. The germinating and seedling growth periods were longer for African boxthorn than for tomato.

\section{Experimental procedures used in EPG assays}

All EPG recordings were conducted at PFR, Mt Albert, New Zealand using concurrently a Giga- 4 and Giga- 8 DC-EPG monitor (EPG Systems, Wageningen, Netherlands). The Giga-4 monitor was connected to African boxthorn plants and the Giga- 8 monitor to tomato plants, to be able to test plants and insects at the same time. The signals from Giga-4 EPG monitor were digitized using the analogue-to-digital device DATAQ Di-720 card (Dataq ${ }^{\circledR}$ Instruments, Akron, $\mathrm{OH}, \mathrm{USA}$ ) and data were acquired and stored using WinDaq/ $\mathrm{Pro}^{+}$software (Dataq ${ }^{\circledR}$ Instruments, Akron, OH, USA). The data from Giga-8 DC-EPG monitor were acquired and stored using Stylet $+d$ for Windows 7 (EPG Systems, Wageningen, Netherlands). Faraday cages were used in all cases to reduce electrical interference and the experiments took place in a climate-controlled room at $21^{\circ} \mathrm{C} \pm 1$, under fluorescent lights with $16 \mathrm{~h}$ photoperiod (6:00-am to 10:00-pm).

Bactericera cockerelli females collected from colony cages were starved for about $4 \mathrm{~h}$ and then anaesthetized with $\mathrm{CO}_{2}$ for ca. five seconds. Psyllids were then immobilized using fine forceps by carefully seizing the back of their wings to allow the attachment of a gold wire $(3 \mathrm{~cm}$ long and $18.0 \mu \mathrm{m}$ diameter) using a water-based silver conductive glue (EPG Systems, Wageningen, The Netherlands) applied on the psyllids' pronotum using a micropin. Once wired psyllids were left for another 20-30 min of recovery period to reduce any potential tethering effect (Lei et al. 1997). Each wired psyllid was placed on the abaxial side of leaves which had been secured to a plastic stand to expose this side and left to feed on the test plants overnight (the EPG recordings were based on $12 \mathrm{~h}$ recording periods between 6:00-pm and 6:00-am next day with $16 \mathrm{~h}$ photoperiod (6:00-am to 10:00-pm). The leaves chosen for EPG were fully expanded young and mature leaves for tomato and African boxthorn, respectively. Older leaves of African boxthorn were chosen as they did not break off from the plant when exposing the underside of the leaves (younger leaves tended to break off the plant).

We tested four psyllid/host plant combinations; infected and uninfected psyllids on tomatoes and African boxthorn. The total number of psyllids tested for the African boxthorn 
EPG assays was 48 (24 infected and 24 non-infected psyllids) and 64 psyllids for the tomato EPG assays (32 infected and 32 non-infected psyllids). Any recordings which were disturbed by psyllids trying to escape from the wire attachment were not included in the analyses. The final number of psyllids that produced EPG recordings suitable for analyses was 18 and 19 infected and,17 and 18 non-infected psyllids tested on tomato and African boxthorn for each infection group, respectively.

All EPG recordings were set at $100 \times$ gain and voltage was adjusted to $1 \mathrm{~V}$ approximately during the initial phases of probing. Once the recordings had taken place, waveform interpretation and measurements were performed using WinDaq Waveform Browser (Dataq ${ }^{\circledR}$ Instruments, Akron, $\mathrm{OH}, \mathrm{USA}$ ) and Stylet + a (EPG Systems, Wageningen, The Netherlands) for the Giga-4 and Giga- 8 DC monitors, respectively. The program Stylet $+a$, developed for aphids does not have the D waveform. Nevertheless, we used this program and substituted the waveform E1e for D. We did not individually analyse waveforms A, B (initial waveforms related to the establishment of electrical contact between the stylet and plant tissues shortly after penetration) (Cen et al. 2012) and $Z$ (waveform related to walking activities) (Youn et al. 2011). Therefore our $\mathrm{C}$ waveform analyses included waveforms A and B and our NP waveform analyses included waveform $\mathrm{Z}$. The term salivation is used throughout the manuscript and refers to salivation in phloem tissue (E1) followed or not followed by phloem ingestion (E2), the latter referred to as single salivation (single E1). Also, the full $12 \mathrm{~h}$ of recording was counted from beginning to end, which included the artificially terminated waveforms at the end of the recording. Waveforms measured were: NP (nonprobing), $\mathrm{C}$ (pathway phase through epidermis and parenchyma), D (first contact with sieve elements), E1 (salivation in sieve elements), E2 (ingestion from phloem tissue) and G (ingestion from xylem tissue).

Selected sequential and non-sequential variables were calculated using "Sarria" Excel workbook (Sarria et al. 2009) and were used for the comparative analysis of feeding differences between hosts and between CLso-infected and non-infected psyllids. We analysed the proportion of individual psyllids that produced each waveform type (waveforms D, E1, single E1, E2, sustained E2 and G; with single E1 being E1 not followed by E2 and sustained E2 being E2 $>10 \mathrm{~min}$ ), and EPG variables as determined by Sarria et al. (2009). These were (i) the time spent (as percentage of total probing) in each waveform type (waveforms $\mathrm{C}, \mathrm{D}$, $\mathrm{E} 1, \mathrm{E} 2$, sustained $\mathrm{E} 2$, and G), (ii) the mean number of waveform events produced per psyllid (in waveforms NP, C, D, E1, single E1, E2 and G), and (iii) the mean duration of waveform events produced per psyllid (in waveforms NP, C, D, E1, E2 and G). Along the non-sequential variables, we calculated the sequential variables (iv) the number of probes before and after the $1 \mathrm{st} \mathrm{E} 1,(\mathrm{v})$ the time to 1 st probe from start of EPG, vi) the time from 1st probe to 1st E1, (vii) the time from 1 st probe to 1 st E2, and viii) the time from 1st probe to 1st sustained E2. Probe is defined in Sarria et al. (2009); a probe $=$ number of waveforms between nonprobing events. Waveform terminology and putative stylet tip position in plant tissue follow (Bonani et al. 2010). The choice of EPG variables was based on previous studies that tested the effects of multiple hosts and CLso infection status on feeding behaviour of its psyllid vector (Sandanayaka et al. 2013, 2014, 2017).

\section{Statistical analyses}

All sequential and non-sequential variables were initially plotted using boxplots with groups (Plant: African boxthorn and tomato; Infection status of psyllid: Yes/No) to illustrate any potential treatment differences, complementing the formal analyses to follow (boxplots were plotted using R). These variables were then formally analysed using analysis of variance (ANOVA) for continuous variables and nonparametric Kruskal-Wallis ANOVA for discrete/count data.

For the number of psyllids that produced each waveform type, a logistic regression was fitted, and odds ratio was calculated from the regression parameters. From these odds ratio, the probability of the number of psyllids that produced each waveform type for each of the treatment combinations were calculated using the odds ratio via the formula $p=\left(\frac{e^{z}}{1+e^{z}}\right)$ where $p=$ probability and $z$ is the relevant odd ratios for each treatment combination.

For ANOVA analyses, Plant (with two levels: African boxthorn and tomato) and Infection status of psyllid (with two levels: Yes/No) was modelled as the Treatment structure (Plant $\times$ Infection). There was no block structure. All residual values were examined graphically to ensure normality and homogeneity of variances. Observations with standardized residuals greater than 3.0 were excluded from analyses. Fisher's protected LSD test $(p<0.05)$ was used to separate means where $F$ tests were significant. We report Fisher's protected LSDs and H-statistics for all cases (that is whether they were significant of not) so that readers can conduct their own pair-wise comparisons. To confirm/check the $F$-probabilities (because of the relatively small number of residual degrees of freedom in the ANOVA), a permutation test with 5000 iterations were also performed. Where appropriate, non-sequential and sequential parameters were log-transformed to homogenize variances and normalize the data. For Kruskal-Wallis ANOVA analyses, Plant*Infection was modelled as the Group factor and ranks were calculated. The differences between the ranks for the four groups were then compared using the test statistic $\mathrm{H}$. All analyses were 
performed in GenStat 18th Edition (VSN International n.d.). Figures were created using R.

\section{Results}

\section{EPG waveforms}

Females of B. cockerelli showed six different EPG waveforms on both host plant species and were identical to waveforms previously described from this psyllid (Pearson et al. 2010, 2014; Sandanayaka et al. 2011). Waveforms observed in this study comprised of waveforms NP (non-probing), $\mathrm{C}$ (pathway phase through epidermis and parenchyma), D (first contact with sieve elements), E1 (salivation in sieve elements), E2 (ingestion from phloem tissue) and G (ingestion from xylem tissue). Hereafter, activities in the sieve elements refer to activities carried out in D, E1 (including single E1 where appropriate) and E2 (including sustained E2 where appropriate).

\section{Number of psyllids displaying a particular waveform}

The number of psyllids that produced a waveform was not affected by host plant type, but there was an effect due to psyllid CLso infection status with more psyllids carrying out sieve element activities when infected with CLso by comparison to the non-infected group (Table 1). The number of psyllids that carried out xylem tissue activities was the same for all groups ( 21 psyllids) but more psyllids carried out xylem activities by comparison to sieve element activities (Table 1). All psyllids carried out non-probing and pathway phase activities (data not shown)

Analyses between the four psyllid infection/host plant groups showed a greater number of psyllids carrying out sieve element activities when infected with CLso tested on African boxthorn followed by tomato (Table 1).

\section{Time spent in each waveform type (\%)}

Comparative analyses of percentage time spent in each waveform type revealed there were no effects of host plant species for any of the waveforms, but there were significant effects of psyllid CLso infection status on time spent in the sieve elements. For instance, time spent in E1 increased 13 times approximately by comparison to the non-infected group (Table 2).

Further analyses between the four psyllid infection/host plant groups revealed that infected psyllids feeding on African boxthorn spent more time in the sieve elements by comparison to any psyllid infection/host plant group combination. For this group, time spent in D, E1 and E2 increased 13, 100 and 3 times approximately for each waveform type, respectively, by comparison to the non-infected group also feeding on the same host plant (Table 2). Similar results were observed for the same group tested on tomato. Boxplots show the distribution of the data used for calculating percentage time spent in each waveform type for each psyllid infection/host plant group (Fig. 1).

Table 1 Proportion and probability (in parentheses) of Candidatus Liberibacter solanacearum-infected and non-infected Bactericera cockerelli producing a waveform during electrical penetration graph assays on leaves of either tomato or African boxthorn

\begin{tabular}{|c|c|c|c|c|c|c|}
\hline EPG experimental conditions & $\mathrm{D}$ & E1 & Single E1 & E2 & Sustained E2 & $\mathrm{G}$ \\
\hline \multicolumn{7}{|l|}{ Host plant } \\
\hline Tomato $(n=35)$ & $17 / 35$ & $16 / 35$ & $16 / 35$ & $13 / 35$ & $7 / 35$ & $21 / 35$ \\
\hline African boxthorn $(n=37)$ & $17 / 37$ & $16 / 37$ & $15 / 37$ & $13 / 37$ & $7 / 37$ & $21 / 37$ \\
\hline$F$ test probability & 0.972 & 0.994 & 0.718 & 0.997 & 0.994 & 0.794 \\
\hline \multicolumn{7}{|l|}{ Psyllid CLso infection status } \\
\hline $\mathrm{TPP}^{-}(n=35)$ & $9 / 35$ & $8 / 35$ & $7 / 35$ & $6 / 35$ & $1 / 35$ & $21 / 35$ \\
\hline $\mathrm{TPP}^{+}(n=37)$ & $25 / 37$ & $24 / 37$ & $24 / 37$ & $20 / 37$ & $13 / 37$ & $21 / 37$ \\
\hline$F$ test probability & 0.001 & 0.002 & 0.001 & 0.002 & 0.001 & 0.756 \\
\hline Interaction & 0.146 & 0.303 & 0.150 & 0.244 & 0.261 & 0.023 \\
\hline \multicolumn{7}{|c|}{ Host plant and psyllid CLso infection status } \\
\hline Tomato/TPP ${ }^{-}(n=17)$ & $6 / 17(0.353)$ & $5 / 17(0.295)$ & $5 / 17(0.295)$ & $4 / 17(0.235)$ & $1 / 17(0.058)$ & $8 / 17(0.470)$ \\
\hline Tomato/TPP ${ }^{+}(n=18)$ & $11 / 18(0.611)$ & $11 / 18(0.611)$ & $11 / 18(0.611)$ & $9 / 18(0.500)$ & $6 / 18(0.333)$ & $13 / 18(0.722)$ \\
\hline African boxthorn/TPP ${ }^{-}(n=18)$ & $3 / 18(0.167)$ & $3 / 18(0.167)$ & $2 / 18(0.111)$ & $2 / 18(0.111)$ & $0 / 18(0.000)$ & $13 / 18(0.722)$ \\
\hline African boxthorn/TPP ${ }^{+}(n=19)$ & $14 / 19(0.737)$ & $13 / 19(0.684)$ & $13 / 19(0.684)$ & $11 / 19(0.579)$ & $7 / 19(0.368)$ & $8 / 19(0.421)$ \\
\hline
\end{tabular}

Probability of psyllids producing a waveform type was calculated from the regression parameters from a logistic regression

$T P P$ non-infected B. cockerelli, $T P P^{+}$CLso-infected B. cockerelli. Waveforms, $D$ first contact with sieve elements, $E 1$ salivation in the sieve elements, single E1 E1 not followed by E2, E2 ingestion from phloem tissue, sustained E2 E2 > 10 min, $G$ ingestion from xylem tissue 
Table 2 Time spent in each waveform type $(\%)$ of Bactericera cockerelli by host plant and psyllid Candidatus Liberibacter solanacearum infection status

\begin{tabular}{|c|c|c|c|c|c|c|}
\hline EPG experimental conditions & $\mathrm{C}$ & $\mathrm{D}$ & E1 & E2 & Sustained E2 & G \\
\hline \multicolumn{7}{|l|}{ Host plant } \\
\hline Tomato $(n=35)$ & 82 & $0.20(37)$ & $2.12(37)$ & $12(37)$ & $17(38)$ & $4(36)$ \\
\hline African boxthorn $(n=37)$ & 81 & $0.21(36)$ & $2.60(36)$ & $8(36)$ & $13(35)$ & $8(37)$ \\
\hline LSD (5\%), (H-statistics) & 11 & 0.03 & 0.02 & 0.14 & 0.33 & 0.03 \\
\hline$F$ test probability, (Chi-square probability) & 0.833 & 0.839 & 0.866 & 0.661 & 0.467 & 0.837 \\
\hline \multicolumn{7}{|l|}{ Psyllid CLso infection status } \\
\hline $\mathrm{TPP}^{-}(n=35)$ & 84 & $0.06(27)$ & $0.32(27)$ & $8(31)$ & $12(33)$ & $8(39)$ \\
\hline $\mathrm{TPP}^{+}(n=37)$ & 79 & $0.35(45)$ & $4.30(46)$ & $12(42)$ & $17(39)$ & $4(34)$ \\
\hline $\begin{array}{l}\text { LSD (5\%), } \\
\text { (H-statistics) }\end{array}$ & 11 & 13.45 & 14.37 & 5.28 & 1.56 & 1.23 \\
\hline$F$ test probability, (Chi-square probability) & 0.382 & $<0.001$ & $<0.001$ & 0.008 & 0.113 & 0.247 \\
\hline \multicolumn{7}{|l|}{ Host plant and psyllid CLso infection status } \\
\hline Tomato/TPP ${ }^{-}(n=17)$ & 83 & $0.09(31)$ & $0.61(30)$ & $11(33)$ & $17(36)$ & $5(33)$ \\
\hline Tomato/TPP ${ }^{+}(n=18)$ & 81 & $0.31(42)$ & $3.54(43)$ & $12(41)$ & $18(40)$ & $4(39)$ \\
\hline African boxthorn/TPP ${ }^{-}(n=18)$ & 84 & $0.03(23)$ & $0.05(24)$ & $4(28)$ & $8(31)$ & $11(45)$ \\
\hline African boxthorn/TPP ${ }^{+}(n=19)$ & 78 & $0.39(48)$ & $5.01(48)$ & $13(43)$ & $17(39)$ & $4(29)$ \\
\hline $\begin{array}{l}\text { LSD (5\%), } \\
\text { (H-statistics) }\end{array}$ & 15 & 15.48 & 15.64 & 5.94 & 2.05 & 5.84 \\
\hline$F$ test probability, (Chi-square probability) & 0.674 & $<0.001$ & $<0.001$ & 0.045 & 0.349 & 0.096 \\
\hline
\end{tabular}

Data are expressed as means. One-way ANOVA (F-statistics) was used for waveform C. Kruskal-Wallis one-way ANOVA was calculated for the remaining waveforms. In these cases, we report the raw mean followed by the mean rank in parentheses, as well as H-statistics and Chi-square probability

$T P P$ non-infected $B$. cockerelli, TPP ${ }^{+}$CLso-infected $B$. cockerelli. Waveforms, $C$ pathway phase, $D$ first contact with sieve elements, E1salivation in the sieve elements, E2 ingestion from phloem tissues, sustained E2 E2 > 10 min, $G$ ingestion from xylem tissues

\section{Number of EPG waveforms}

Analyses of the number of waveforms showed there was no effect of host plant species but there was a significant effect of psyllid CLso infection status on the number of non-probing, pathway and sieve element events. In all these tissues, the number of waveforms increased significantly in the infected group. For instance, there were 5 , 7, 8.5 times more Ds, E1s and single E1s, 5 times more E2s and 2 times more non-probing and pathway events (Table 3).

Analyses between the four psyllid infection/host plant groups showed a significant increase in the number of the waveforms mentioned above by the infected psyllid group tested on African boxthorn. For instance, the number of Ds, E1s and E2s increased by up to 12, 17 and 9 times for each waveform type, respectively (Table 3 ). Salivation not followed by phloem ingestion also increased significantly for the same group by up to 30 times (Table 3 ). Boxplots show the distribution of the data used for calculating the number of waveform events for each pathogen-host group and EPG waveform type (Fig. 2).

\section{Duration of EPG waveforms}

There was no effect of plant species on the duration of waveforms, except for the duration of the pathway phase that was shorter on African boxthorn by comparison to tomato, although the difference was marginal $(p=0.038)$ (Table 4). By contrast, there was a significant effect of CLso psyllid infection status on the duration of all sieve element waveform types. For instance, duration of salivation increased 11 times in the infected group whilst ingestion from phloem tissue decreased by 1.5 times in the infected psyllid group (Table 4).

Analyses between the four psyllid infection/host plant groups revealed significantly longer duration of salivation carried out by infected psyllids feeding on African boxthorn. For instance, the duration of salivation increased 71 times in this group when compared to the uninfected group feeding on the same host plant (Table 4). The duration of phloem ingestion decreased by up to 1.4 times in this group, although the difference was marginal $(p=0.048)$ 

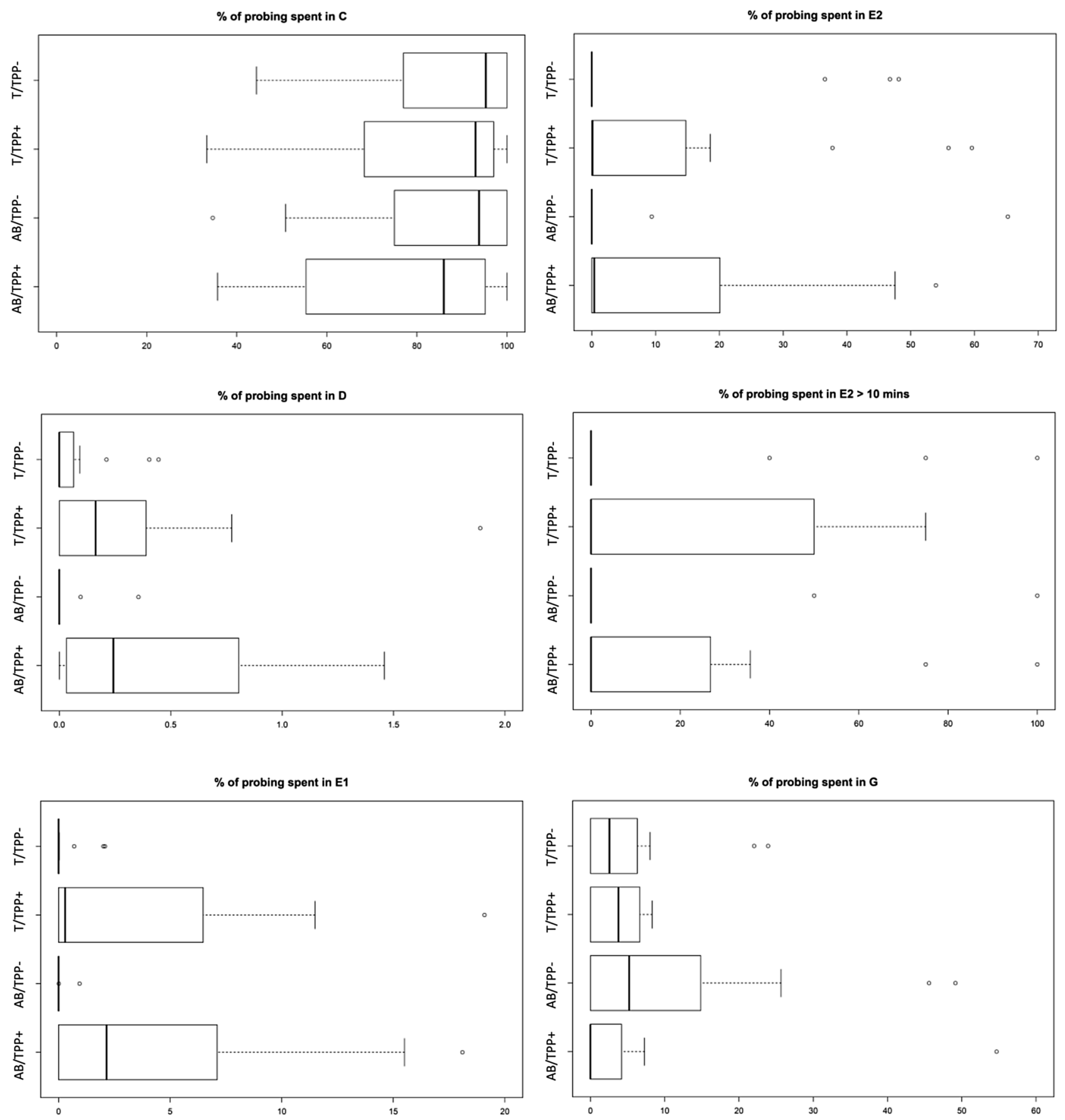

Fig. 1 Time spent in each waveform type (\%) of Candidatus Liberibacter solanacearum-infected and non-infected Bactericera cockerelli during electrical penetration graph assays on leaves of either tomato or African boxthorn. T/TPP ${ }^{-}$Tomato/non-infected B. cockerelli $(n=17), T / T P P^{+}$Tomato/CLso infected B. cockerelli $(n=18), A B /$

(Table 4). Boxplots show the distribution of the data used for calculating durations of non-probing and waveform

$T P P^{-}$African boxthorn/non-infected B. cockerelli $(n=18), A B / T P P^{+}$ African boxthorn/CLso-infected $B$. cockerelli $(n=19)$. Waveforms, $C$ pathway phase, $D$ first contact with sieve elements, $E 1$ salivation in the sieve elements, E2 ingestion from phloem tissues, sustained E2 E2 $>10$ min, $G$ ingestion from xylem tissues

events for each pathogen-host group and EPG waveform type (Fig. 3). 
Table 3 Number of waveform events of Bactericera cockerelli by host plant and psyllid Candidatus Liberibacter solanacearum infection status for each EPG waveform

\begin{tabular}{|c|c|c|c|c|c|c|c|}
\hline EPG experimental conditions & NP & $\mathrm{C}$ & $\mathrm{D}$ & E1 & Single E1 & E2 & G \\
\hline \multicolumn{8}{|l|}{ Host plant } \\
\hline Tomato $(n=35)$ & 11 & 13 & $1.9(37)$ & $2.7(37)$ & $1.0(37)$ & $1.5(37)$ & $0.8(37)$ \\
\hline African boxthorn $(n=7)$ & 16 & 18 & $1.9(36)$ & $2.8(36)$ & $0.9(36)$ & $1.5(36)$ & $1.0(36)$ \\
\hline LSD (5\%), (H-statistics) & 5 & 5 & 0.08 & 0.07 & 0.07 & 0.02 & 0.018 \\
\hline$F$ test probability, (Chi-square probability) & 0.070 & 0.079 & 0.754 & 0.764 & 0.739 & 0.849 & 0.884 \\
\hline \multicolumn{8}{|l|}{ Psyllid CLso infection status } \\
\hline $\mathrm{TPP}^{-}(n=35)$ & 9 & 11 & $0.6(28)$ & $0.7(27)$ & $0.2(29)$ & $0.5(29)$ & $0.9(37)$ \\
\hline $\mathrm{TPP}^{+}(n=37)$ & 17 & 21 & $3.1(45)$ & $4.8(45)$ & $1.7(44)$ & $2.4(43)$ & $0.9(36)$ \\
\hline LSD (5\%), (H-statistics) & 5 & 5 & 12.04 & 12.56 & 9.77 & 8.28 & 0.009 \\
\hline$F$ test probability, (Chi-square probability) & 0.004 & $<0.001$ & $<0.001$ & $<0.001$ & $<0.001$ & $<0.001$ & 0.918 \\
\hline \multicolumn{8}{|l|}{ Host plant and psyllid CLso infection status } \\
\hline Tomato/TPP ${ }^{-}(n=17)$ & 10 & 11 & $0.9(32)$ & $1.2(31)$ & $0.3(32)$ & $0.8(32)$ & $0.8(33)$ \\
\hline Tomato/TPP ${ }^{+}(n=18)$ & 12 & 15 & $2.8(42)$ & $4.3(43)$ & $1.7(43)$ & $2.2(42)$ & $0.9(40)$ \\
\hline African boxthorn/TPP ${ }^{-}(n=18)$ & 9 & 10 & $0.3(23)$ & $0.3(24)$ & $0.06(26)$ & $0.3(27)$ & $1.0(40)$ \\
\hline African boxthorn/TPP ${ }^{+}(n=19)$ & 22 & 25 & $3.5(47)$ & $5.2(47)$ & $1.8(45)$ & $2.7(45)$ & $1.0(33)$ \\
\hline LSD (5\%), (H-statistics) & 7 & 8 & 14.13 & 13.69 & 10.68 & 8.87 & 2.04 \\
\hline$F$ test probability, (Chi-square probability) & 0.060 & 0.052 & $<0.001$ & $<0.001$ & 0.002 & 0.007 & 0.500 \\
\hline
\end{tabular}

Data are expressed as means. One-way ANOVA (F-statistics) was used for waveforms NP and C. Kruskal-Wallis one-way ANOVA was calculated for the remaining waveform types. In these cases, we report the raw mean followed by the mean rank in parentheses, as well as H-statistics and Chi-square probability

$T P P$ non-infected $B$. cockerelli, $T P P^{+}$CLso-infected $B$. cockerelli. Waveforms, $N P$ non-probing, $C$ pathway phase, $D$ first contact with sieve elements, $E 1$ salivation in the sieve elements, single E1 E1 not followed by E2, E2 ingestion from phloem tissue, $G$ ingestion from xylem tissue

\section{Sequential EPG variables}

As in previous non-sequential EPG variables there was no effect of plant species on any of the sequential variables examined here, but there was a significant effect due to psyllid infection status on the number of probes before and after the 1st salivation event. Non-infected psyllids probed on average once, whilst CLso-infected psyllids probed 7 and 6 times before and after reaching the sieve elements, respectively (Table 5). There was as well as significant effect in the time elapsed to reach the sieve elements (variables: time from 1st probe to 1st E1 and 1st E2), that decreased from 10 and $11 \mathrm{~h}$ (in the non-infected group) to 8 and $9 \mathrm{~h}$ (in the infected group) for each variable, respectively (Table 5).

Further analyses between the four psyllid infection/ host plant groups revealed a significantly higher number of probes carried out before and after the 1 st salivation event by the infected psyllid group tested on African boxthorn (up to 10 and 7 times more probes for each variable, respectively) (Table 5). However, there were no differences in the remaining sequential variables. All psyllids spent similar time reaching the sieve elements, i.e. 14 to $18 \mathrm{~min}$ to start probing from the beginning of EPG recordings, 7 to $11 \mathrm{~h}$ to reach the sieve elements (variables: time from 1st probe to 1st E1 and E2) and, 10 to $11 \mathrm{~h}$ to initiate prolonged phloem ingestion (Table 5). Boxplots show the distribution of the data used for calculating sequential variables for each pathogen-host group (Fig. 4).

\section{Discussion}

\section{Probing behaviour of CLso-infected and non-infected $B$. cockerelli}

A handful of EPG-based studies have recorded psyllid feeding behaviour when pathogenic Candidatus Liberibacter species are present in the plant (Cen et al. 2012; Sandanayaka et al. 2014; George et al. 2018) or in the insect (Sandanayaka et al. 2014; Antolinez et al. 2017a, b; Killiny et al. 2017). When $C a$. Liberibacter species or haplotypes are present in a psyllid, EPG-based studies have shown changes in feeding. For instance, the duration of the pathway phase, salivation phase and time to reach the sieve elements decreased in CLso-infected B. cockerelli and B. trigonica (Sandanayaka et al. 2014; Antolinez et al. 2017a, b). A third study carried out on Candidatus Liberibacter asiaticus (CLas)infected D. citri (Killiny et al. 2017) also showed a decrease in the duration of the pathway and salivation phases as seen in the B. cockerelli and B. trigonica studies. Our study also showed a decrease in the duration of the pathway phase and time to reach the sieve elements but, in contrast with the 
afore-mentioned studies; an increase in salivation. In our study, CLso-infected psyllids spent more time on phloem ingestion activities by comparison to non-infected ones, an effect also seen in the Bactericera spp. studies. In addition, two of the above-mentioned studies reported an increase in xylem ingestion by $\mathrm{Ca}$. Liberibacter spp.-infected psyllids (Sandanayaka et al. 2014; Killiny et al. 2017), whereas our study found a decrease in xylem ingestion similar to (Antolinez et al. 2017a, b). Possible explanations for the observed differences could be osmotic stresses (Pompon et al. 2011), host plant health (Cen et al. 2012), host mechanical/chemical stimuli (Valenzuela et al. 2017) and plant age (Luo et al. $2015 a, b)$ to mention a few. Our study did not test specific reasons why the feeding behaviour of infected psyllids was different to non-infected ones and to results from some previous studies. But results from other studies are suggestive of the pathogen being capable of altering important physiological processes in the insect such as the ones observed in (Killiny et al. 2017), where increased Adenosine triphosphate (ATP) levels were observed in CLas-infected D. citri adults. Additional physiological changes have also been observed in CLas-infected D. citri nymphs (Killiny and Jones 2018). These or other physiological changes could have contributed to the observed differences in our study, where the pathogen was able to change the feeding behaviour of its vector to presumably promote its spread through faster access to the sieve elements and an increase in salivation and phloem ingestion.

Despite the small number of studies on pathogen mediated feeding changes (particularly of studies based on persistent circulative bacterial pathogens), a pattern is emerging whereby infected insects spent less time in the pathway phase therefore reaching the sieve elements sooner by comparison to a non-infected group. However, it is difficult to find a common pattern of probing activities in the sieve elements and in xylem tissues with results differing depending on the study. For instance, in our study the CLso-infected group salivated significantly more by comparison to the non-infected group but the reverse was seen in other psyllid studies (Sandanayaka et al. 2014; Antolinez et al. 2017a, b; Killiny et al. 2017). This could be explained by different recording periods (from 5 to $24 \mathrm{~h}$ ) used in different studies which may have influenced the results as shown in (Sandanayaka et al. 2017), and other factors like the age of the plant and the type of leaf (Luo et al. 2015a, b; Ebert et al. 2018), the pathogen titre in the plant or the insect, pathogen genotype and insect age.

The molecular interactions that mediate feeding changes are not fully characterized or known for many pathosystems but, with the advent of functional genomics more pathways are being discovered that point out the important role that pathogen related proteins have on the vectors' phenotypic changes (Tamborindeguy et al. 2017; Sackton 2018; Mauck et al. 2019; Sugio et al. 2015; Bernardo and Singer 2017). In absence of 'omics' data and based on other pathosystems, we propose that the feeding effects observed in our study could be due to the result of bacteria-vector specific responses, pointing out to a possible manipulation by the pathogen. This inference, however, needs to be studied further using the appropriate technologies.

We are also aware that plant mediated responses have not been excluded from our study given that our infected group became infected whilst feeding from an infected plant during its entire nymph development. Although difficult to separate, studies have shown that leaving insects to feed on an infected host plant for a short time and preferably during their early stages of development, allows sufficient time for the pathogen to replicate in the insect without the host effects (Moreno-Delafuente et al. 2013; Stafford et al. 2011). Further to this, we are also aware that our psyllids had different rearing and test hosts. Application of the same host plant species for rearing and testing insects may exclude host switching effects from the results. However, it is not uncommon to find experiments that include different rearing and test hosts, as seen in other EPG studies on psyllids (Antolinez et al. 2017a, b; George et al. 2018; Butler et al. 2012) and aphids (Simon et al. 2017). In this study, most test insects were not reared on the same plant type as tested. Rearing TPP on African boxthorn was not feasible as this host does not meet the basic criteria used for long term rearing of psyllids because of its poor germination and development under glasshouse conditions. In addition, leaves drop off easily and complete leaf drop can happen randomly (Vereijssen pers. observation). A preliminary EPG study investigating the effects of switching hosts between tomato and capsicum found no effects on feeding behaviour of TPP due to host switching between these two host plants (Sandanayaka unpublished data).

\section{Implication to potential CLso transmission to tomato and African boxthorn}

Candidatus Liberibacter spp. inoculation studies suggest that successful transmission is dependent on several factors mainly; the acquisition access period, the post-acquisition period where the pathogen replicates inside the insect, the insect life-stage at time of acquisition, and pathogen titre in the plant (Inoue et al. 2009; Pelz-Stelinski et al. 2010; Lopes et al. 2016; George et al. 2018). Our study did not assess CLso transmission to tomato or African boxthorn. A previous study reported successful transmission of CLso to tomato (Sandanayaka et al. 2014). Our results validate the observed transmission of CLso to African boxthorn in laboratory conditions (Dohmen-Vereijssen et al. 2016).

Although not easy, it is important to reduce psyllid probing to avoid the spread of the pathogen. Some insecticides 
662

I. Valenzuela et al.
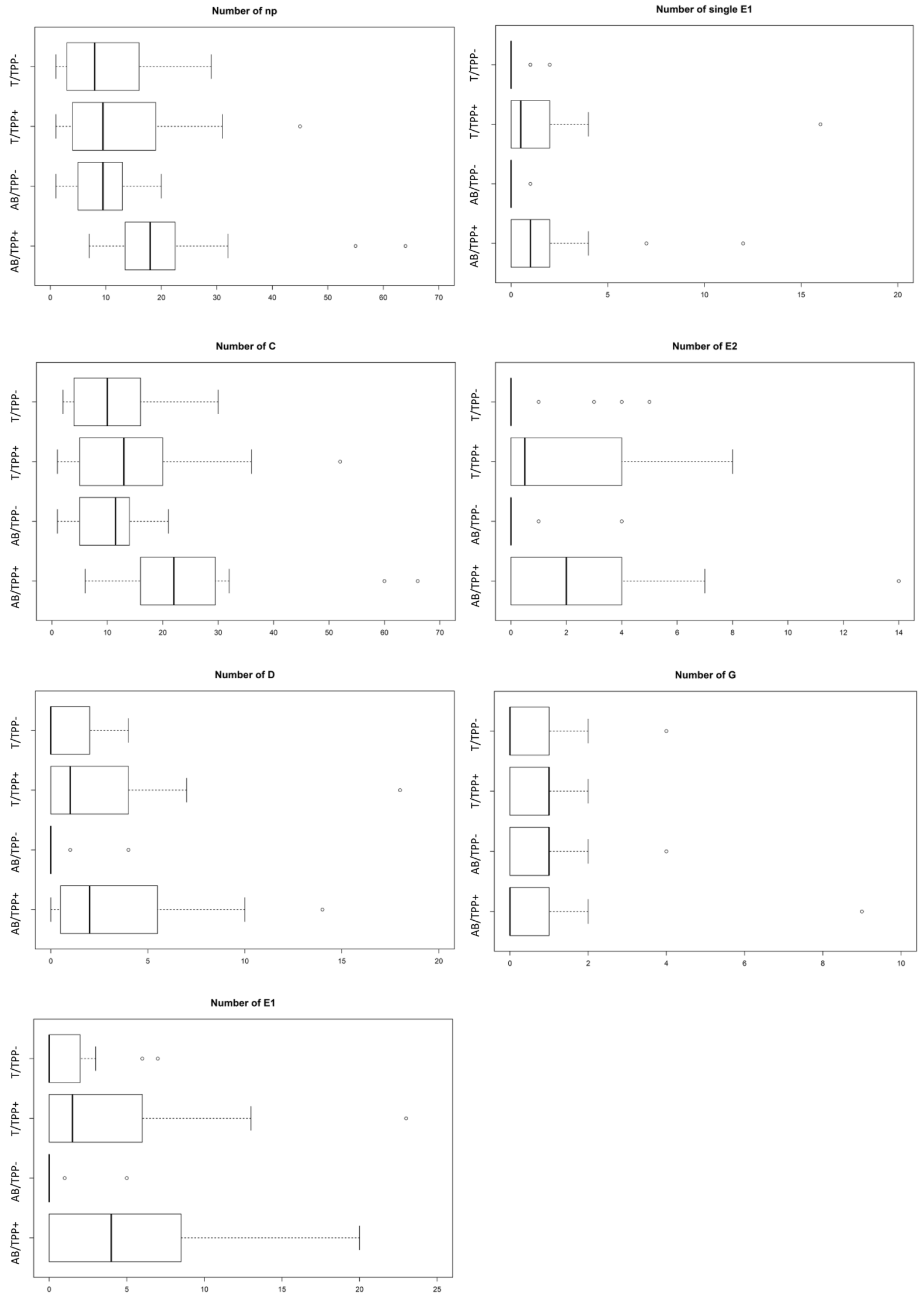

黛 Springer 
४Fig. 2 Number of waveform events of Candidatus Liberibacter solanacearum-infected and non-infected Bactericera cockerelli during electrical penetration graph assays on leaves of tomato or African boxthorn. Tomato/TPP Tomato/non-infected B. cockerelli $(n=17)$, Tomato/TPP ${ }^{+}$Tomato/CLso-infected B. cockerelli $(n=18), A B / T P P^{-}$ African boxthorn/non-infected B. cockerelli $(n=18), A B / T P P^{+}$African boxthorn/CLso-infected B. cockerelli $(n=19)$. Waveforms, $N P$ non-probing, $C$ pathway phase, $D$ first contact with sieve elements, E1 salivation in the sieve elements, single E1 E1 not followed by E2, $E 2$ ingestion from phloem tissue, $G$ ingestion from xylem tissue

have proven relatively effective at controlling/stopping psyllids from feeding such as cyantraniliprole and abamectin sprayed on potatoes (Mustafa et al. 2015a, b), and less effective was soil applied imidacloprid and aldicarb to protect citrus (Serikawa et al. 2012, 2013). Protecting non-crop host plants is more difficult than protecting crops yet they are important in the epidemiology of the disease. A better strategy than spraying insecticides in non-crop hosts, is to eliminate host availability if possible. This becomes important as seen in New Zealand potato crops that had African boxthorn planted along the crops' boundaries as wind breaks. These crops showed high incidences of Zebra chip which was likely due to the movement of infected psyllids from African boxthorn to potatoes and vice versa (Dohmen-Vereijssen et al. 2016). In New Zealand, efforts to control TPP and the pathogen CLso are following integrated pest management strategies which combine cultural, biological and chemical control methods (Vereijssen et al. 2018).

\section{Probing behaviour of $B$. cockerelli on tomato and African boxthorn}

The present study showed there were no effects of host plant species on the probing behaviour of female adult $B$. cockerelli, indicating that physical and chemical stimuli of tomato or African boxthorn did not affect psyllids' probing behaviour during the $12 \mathrm{~h}$ that psyllids were monitored using the EPG technique. This supports the findings from field surveys carried out in New Zealand where large numbers of all life stages of B. cockerelli were found on African boxthorn throughout the year (Vereijssen et al., unpublished data). The presence of African boxthorn in Australia poses a challenge for the management of $B$. cockerelli as African boxthorn is a widespread species in pastures and neglected areas (Noble and Rose 2013; ALA 2018a). Additional Lycium species, which are also abundant in Australia, could become potential hosts for $B$. cockerelli, such as the indigenous $L$. australe which is also widespread (ALA 2018b).

The predominant waveform in B. cockerelli was the pathway phase through epidermis and parenchyma tissues with $82 \%$ and $81 \%$ of the total time spent in this waveform on tomato and African boxthorn, respectively (Table 2).
Table 4 Duration (minutes) of waveform events of Bactericera cockerelli by host plant and psyllid Candidatus Liberibacter solanacearum infection status for each EPG waveform representing different stylet penetration activity. Data are expressed as means. One-way ANOVA (F-statistics) was used for waveforms NP and $\mathrm{C}$, which were log-transformed. The values given are the raw means followed by the log-transformed means in parentheses

\begin{tabular}{|c|c|c|c|c|c|c|}
\hline EPG experimental conditions & NP & $\mathrm{C}$ & $\mathrm{D}^{1}$ & $\mathrm{E} 1^{1}$ & E2 & $\mathrm{G}$ \\
\hline \multicolumn{7}{|l|}{ Host plant } \\
\hline Tomato $(n=35)$ & $19(3.1)$ & $86(3.7)$ & $21(38)$ & $120(37)$ & $23(37)$ & $19(36)$ \\
\hline African boxthorn $(n=37)$ & $10(2.8)$ & $59(3.6)$ & $17(35)$ & $185(36)$ & $24(36)$ & $32(36)$ \\
\hline LSD (5\%), (H-statistics) & 0.5 & 0.4 & 0.28 & 0.03 & 0.11 & 0.00003 \\
\hline$F$ test probability, (Chi-square probability) & 0.666 & 0.038 & 0.560 & 0.827 & 0.699 & 0.995 \\
\hline \multicolumn{7}{|l|}{ Psyllid CLso infection status } \\
\hline $\mathrm{TPP}^{-}(n=35)$ & $11(2.8)$ & $96(3.8)$ & $8(28)$ & $26(27)$ & $28(31)$ & $37(40)$ \\
\hline $\mathrm{TPP}^{+}(n=37)$ & $18(3.0)$ & $50(3.5)$ & $30(44)$ & $274(45)$ & $19(42)$ & $14(33)$ \\
\hline LSD (5\%), (H-statistics) & 0.5 & 0.4 & 11.23 & 14.20 & 5.13 & 2.10 \\
\hline$F$ test probability, (Chi-square probability) & 0.988 & $<0.001$ & $<0.001$ & $<0.001$ & 0.008 & 0.131 \\
\hline \multicolumn{7}{|l|}{ Host plant and psyllid CLso infection status } \\
\hline Tomato/TPP ${ }^{-}(n=17)$ & $13(2.9)$ & $93(3.7)$ & $11(32)$ & $48(30)$ & $30(34)$ & $17(33)$ \\
\hline Tomato/TPP ${ }^{+}(n=18)$ & $25(3.2)$ & $80(3.7)$ & $30(43)$ & $188(43)$ & $17(41)$ & $20(40)$ \\
\hline African boxthorn/TPP ${ }^{-}(n=18)$ & $8(2.7)$ & $100(3.8)$ & $4(24)$ & $5(24)$ & $26(28)$ & $57(47)$ \\
\hline African boxthorn/TPP ${ }^{+}(n=19)$ & $12(2.9)$ & $21(3.1)$ & $29(45)$ & $355(48)$ & $22(43)$ & $9(27)$ \\
\hline LSD (5\%), (H-statistics) & 0.8 & 0.6 & 12.46 & 15.54 & 5.84 & 9.20 \\
\hline$F$ test probability, (Chi-square probability) & 0.503 & 0.026 & 0.002 & $<0.001$ & 0.048 & 0.019 \\
\hline
\end{tabular}

The LSD given is also in log-transformed mode. Kruskal-Wallis one-way ANOVA was conducted for the remainder waveforms. In these cases, we report the raw mean followed by the mean rank in parentheses, as well as $\mathrm{H}$-statistics and Chi-square probability

$T P P^{-}$non-infected B. cockerelli, $T P P^{+}$CLso-infected B. cockerelli. ${ }^{1}$ Waveforms D and E1 are shown in seconds. Waveforms: $N P$ non-probing, $C$ pathway phase, $D$ first contact with sieve elements, $E 1$ salivation in the sieve elements, $E 2$ ingestion from phloem tissue, $G$ ingestion from xylem tissue 

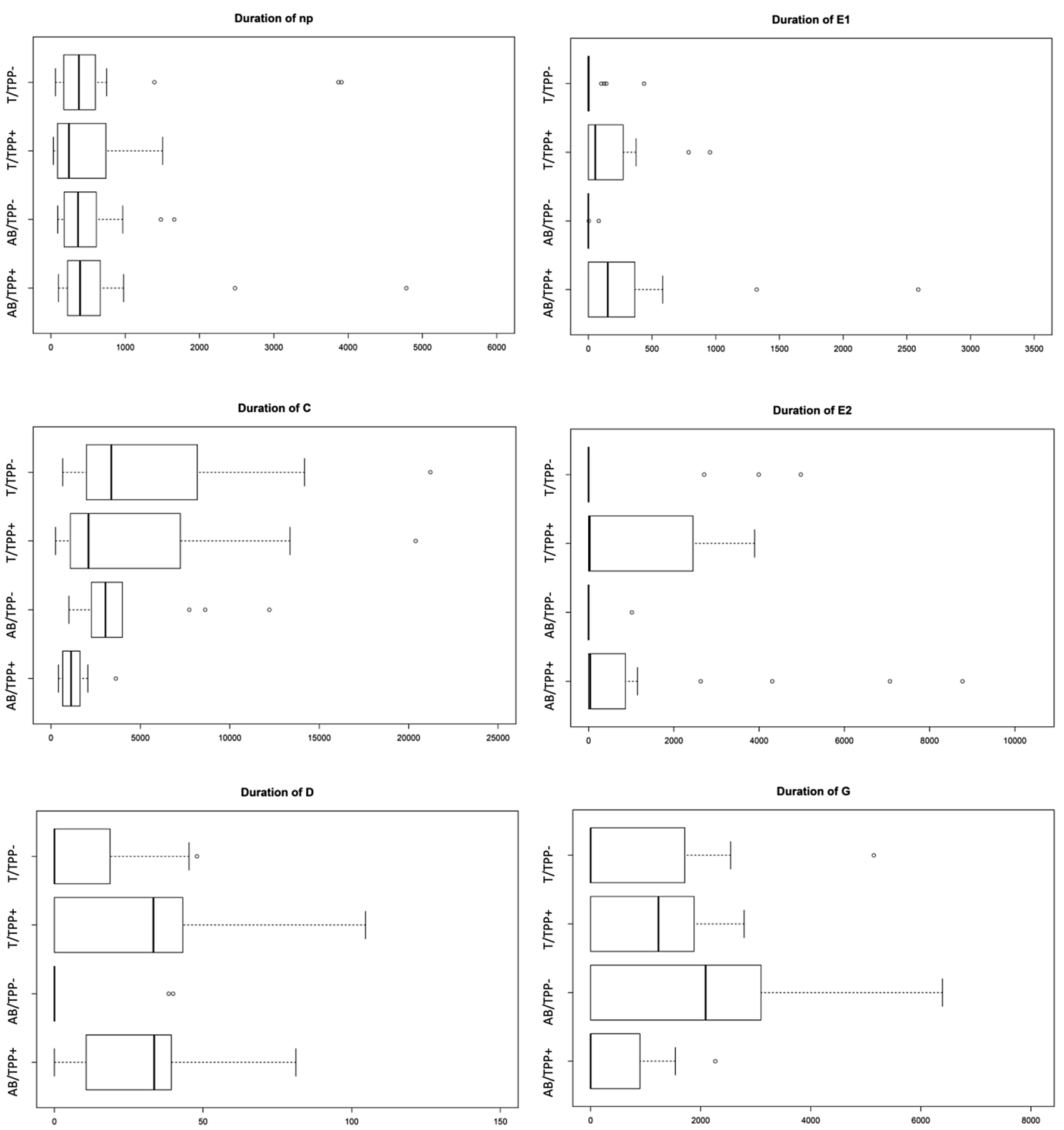

Fig. 3 Duration (seconds) of waveform events of Candidatus Liberibacter solanacearum-infected and non-infected Bactericera cockerelli during electrical penetration graph assays on leaves of tomato or African boxthorn. Tomato/TPP Tomato/non-infected B. cockerelli $(n=17)$, Tomato/TPP ${ }^{+}$Tomato/CLso-infected B. cockerelli $(n=18)$,

Meanwhile, percentage time spent ingesting from phloem tissues occurred less frequently with $12-17 \%$ on tomato and $8-13 \%$ on African boxthorn for each waveform type, respectively (Table 2 ). This suggests that $B$. cockerelli either (i) preferred feeding from the parenchyma (unlikely

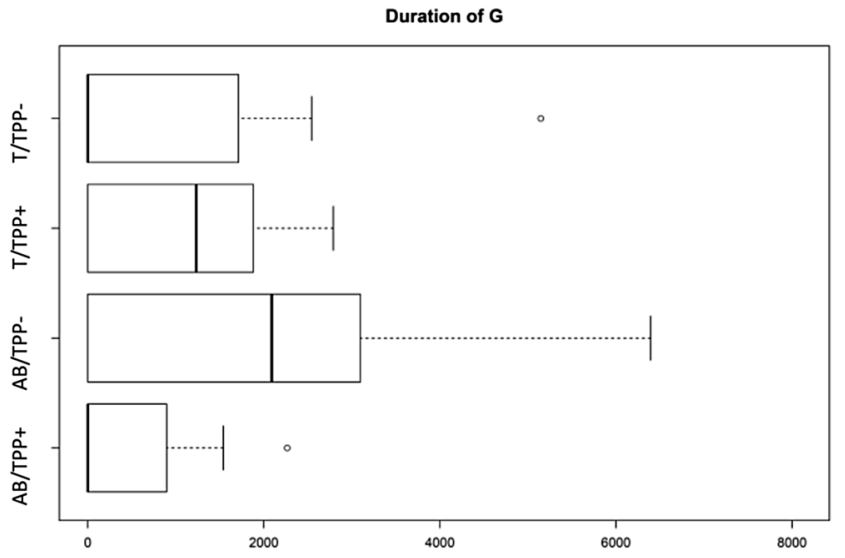

$A B / T P P^{-}$African boxthorn/non-infected B. cockerelli $(n=18), A B /$ $T P P^{+}$African boxthorn/CLso-infected B. cockerelli $(n=19)$. Waveforms, $N P$ non-probing, $C$ pathway phase, $D$ first contact with sieve elements, E1 salivation in the sieve elements, E2 ingestion from phloem tissue, $G$ ingestion from xylem tissue

as previous EPG studies on various hosts, including tomato characterized this species as being predominantly a phloem feeder Butler et al. 2012; Mustafa et al. 2015a, b; Sandanayaka et al. 2014, 2017), or (ii) found some type of impediment that delayed reaching the sieve elements. 
Table 5 Sequential EPG variables of $B$. cockerelli by host plant and by psyllid Candidatus Liberibacter solanacearum infection status

\begin{tabular}{|c|c|c|c|c|c|c|}
\hline $\begin{array}{l}\text { EPG experimental } \\
\text { conditions }\end{array}$ & $\begin{array}{l}\text { Number of } \\
\text { probes before } \\
1 \text { st E1 }\end{array}$ & $\begin{array}{l}\text { Number of } \\
\text { probes after } \\
1 \text { st E1 }\end{array}$ & $\begin{array}{l}\text { Time to } 1 \text { st probe from } \\
\text { start of EPG recording } \\
\text { (min) }\end{array}$ & $\begin{array}{l}\text { Time from 1st } \\
\text { probe to 1st E1 } \\
\text { (h) }\end{array}$ & $\begin{array}{l}\text { Time from 1st } \\
\text { probe to 1st E2 } \\
\text { (h) }\end{array}$ & $\begin{array}{l}\text { Time from 1st probe } \\
\text { to 1st sustained E2 } \\
\text { (h) }\end{array}$ \\
\hline \multicolumn{7}{|l|}{ Host plant } \\
\hline Tomato $(n=35)$ & $3(36)$ & $3(37)$ & $15(2.9)$ & $9(4.5)$ & $9(4.5)$ & $10(4.5)$ \\
\hline $\begin{array}{l}\text { African boxthorn } \\
\quad(n=37)\end{array}$ & $5(37)$ & $4(36)$ & $16(3.0)$ & $9(4.5)$ & $10(4.5)$ & $10(4.6)$ \\
\hline $\begin{array}{l}\text { LSD (5\%), (H-sta- } \\
\text { tistics) }\end{array}$ & 0.0008 & 0.02 & 0.75 & 0.36 & 0.31 & 0.30 \\
\hline $\begin{array}{l}F \text { test probability, } \\
\text { (Chi-square prob- } \\
\text { ability) }\end{array}$ & 0.975 & 0.844 & 0.789 & 0.795 & 0.823 & 0.383 \\
\hline \multicolumn{7}{|c|}{ Psyllid CLso infection status } \\
\hline $\mathrm{TPP}^{-}(n=35)$ & $1(27)$ & $1(31)$ & $14(2.9)$ & $10(4.6)$ & $11(4.6)$ & $11(4.6)$ \\
\hline $\mathrm{TPP}^{+}(n=37)$ & $7(46)$ & $6(42)$ & $17(3.0)$ & $8(4.5)$ & $9(4.5)$ & $10(4.5)$ \\
\hline $\begin{array}{l}\text { LSD (5\%), (H-sta- } \\
\text { tistics) }\end{array}$ & 14.59 & 5.15 & 0.75 & 0.36 & 0.31 & 0.30 \\
\hline $\begin{array}{l}F \text { test probability, } \\
\text { (Chi-square prob- } \\
\text { ability) }\end{array}$ & $<0.001$ & 0.003 & 0.653 & 0.025 & 0.039 & 0.271 \\
\hline \multicolumn{7}{|c|}{ Host plant and psyllid CLso infection status } \\
\hline Tomato/TPP ${ }^{-}(n=17)$ & $1(29)$ & $1(35)$ & $14(2.9)$ & $9(4.5)$ & $10(4.5)$ & $10(4.5)$ \\
\hline Tomato/TPP ${ }^{+}(n=18)$ & $5(43)$ & $4(39)$ & $16(3.0)$ & $9(4.5)$ & $9(4.5)$ & $10(4.5)$ \\
\hline $\begin{array}{l}\text { African boxthorn/ } \\
\operatorname{TPP}^{-}(n=18)\end{array}$ & $1(25)$ & $0(27)$ & $15(2.9)$ & $11(4.6)$ & $11(4.6)$ & $11(4.6)$ \\
\hline $\begin{array}{l}\text { African boxthorn/ } \\
\operatorname{TPP}^{+}(n=19)\end{array}$ & $10(48)$ & $7(45)$ & $18(3.0)$ & $7(4.4)$ & $8(4.5)$ & $10(4.5)$ \\
\hline $\begin{array}{l}\text { LSD (5\%), (H-sta- } \\
\text { tistics) }\end{array}$ & 15.38 & 7.06 & 1.06 & 0.51 & 0.43 & 0.42 \\
\hline $\begin{array}{l}F \text { test probability, } \\
\text { (Chi-square prob- } \\
\text { ability) }\end{array}$ & $<0.001$ & 0.008 & 0.934 & 0.082 & 0.161 & 0.411 \\
\hline
\end{tabular}

Data are expressed as means. Kruskal-Wallis one-way ANOVA was calculated for variables: Number of probes to the 1st E1 and number of probes after the 1st E1. In these cases, we report the raw mean followed by the mean rank in parentheses, as well as H-statistics and Chi-square probability. One-way ANOVA (F-statistics) was used for the remainder variables which were log-transformed (the values given are the raw means followed by the log-transformed means in parentheses). LSDs are given in log-scale

$T P P^{-}$non-infected $B$. cockerelli, $T P P^{+}$CLso-infected B. cockerelli. E1 salivation in the sieve elements, E2 ingestion from phloem tissue, sustained E2 E2>10 min

This line of evidence is supported by the long-time psyllids took to reach the sieve elements on both hosts; psyllids took $9-10 \mathrm{~h}$ to reach the sieve elements and $10 \mathrm{~h}$ to initiate sustained phloem ingestion (Table 5). This contrasts with previous $B$. cockerelli feeding studies that reported shorter times for the same variables. For instance, when feeding on potato, B. cockerelli took 2.6 to $4.2 \mathrm{~h}$ to 1 st phloem salivation and 3.2 to $5.5 \mathrm{~h}$ to $1 \mathrm{st}$ phloem ingestion (Butler, Walker and Trumble 2012; Mustafa et al. 2015a, b) and when feeding on tomato, B. cockerelli took $2.1 \mathrm{~h}$ to $1 \mathrm{st}$ phloem salivation and 1.1 to $6.3 \mathrm{~h}$ to 1 st phloem ingestion (Sandanayaka et al. 2011, 2014).

It is not clear why reaching the sieve elements was delayed in our study by comparison to other studies. Given the longer times reported here $(9-10 \mathrm{~h}$ to reach the sieve elements and $10 \mathrm{~h}$ to initiate prolonged phloem ingestion), we recommend that EPG recordings using B. cockerelli is carried out for a minimum of $12 \mathrm{~h}$ particularly, in phloem-restricted pathogen transmission and acquisition experiments, as well as measuring effectiveness of systemic insecticides and assessing phloem-based host plant resistance.

\section{Conclusion}

The present study showed there was an effect of psyllid infection status on probing behaviour. In summary, more psyllids carried out probing activities in the sieve elements 

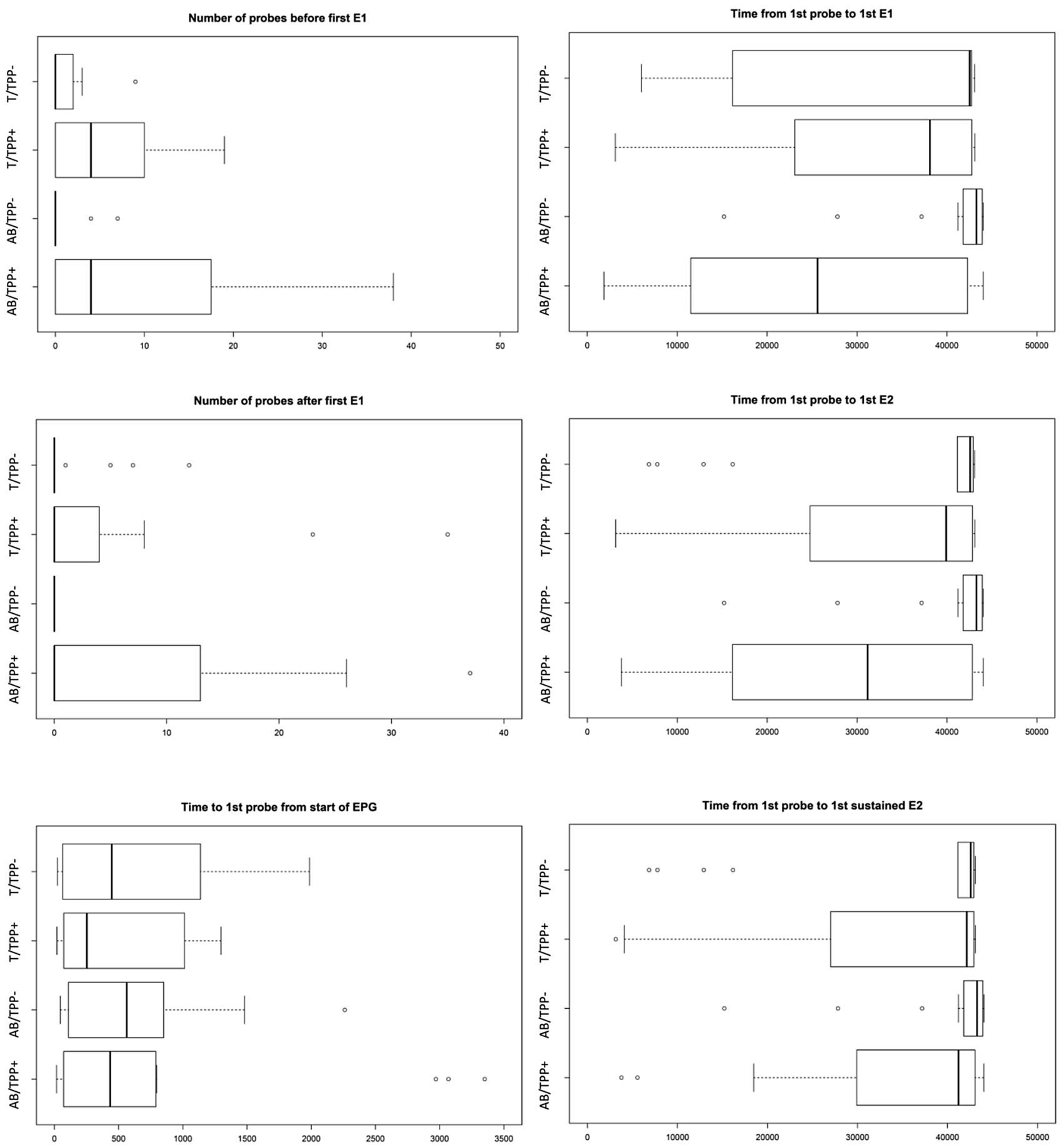

Fig. 4 Sequential EPG variables of Candidatus Liberibacter solanacearum-infected and non-infected Bactericera cockerelli during electrical penetration graph assays on leaves of tomato or African boxthorn. Tomato/TPP $P^{-}$Tomato/non-infected B. cockerelli $(n=17)$, Tomato/TPP ${ }^{+}$Tomato/CLso-infected B. cockerelli $(n=18), \mathrm{AB} /$ $\mathrm{TPP}^{-}=$African boxthorn/non-infected $B$. cockerelli $(n=18), A B /$

when infected with CLso and more probing activities were observed from the CLso-infected psyllid group by comparison to the non-infected group. These findings are important

$T P P^{+}$African boxthorn/CLso-infected B. cockerelli $(n=19)$. Sequential variables: number of probes before and after the 1st salivation event (E1), time to 1st probe from start of EPG recording, time from 1st probe to 1st E1, 1st E2 and 1st sustained E2. Waveforms: E1 salivation in the sieve elements, $E 2$ ingestion from phloem tissue; sustained $E 2 \mathrm{E} 2>10 \mathrm{~min}$

for understanding pathogen and disease epidemiology as an increase in salivation and ingestion activities has the potential to intensify pathogen transmission and acquisition rates. 
But further studies are needed to elucidate the molecular interactions that induced such changes, considering potential host plant effects.

Acknowledgements This manuscript is dedicated to the memory of Alan L. Yen who passed away in March 2017. This work was made possible under the Plant Biosecurity Cooperative Research Centre CRC2079 Grant "Understanding the role of alternative host plants in tomato potato psyllid and Liberibacter life cycle and ecology".

Open Access This article is licensed under a Creative Commons Attribution 4.0 International License, which permits use, sharing, adaptation, distribution and reproduction in any medium or format, as long as you give appropriate credit to the original author(s) and the source, provide a link to the Creative Commons licence, and indicate if changes were made. The images or other third party material in this article are included in the article's Creative Commons licence, unless indicated otherwise in a credit line to the material. If material is not included in the article's Creative Commons licence and your intended use is not permitted by statutory regulation or exceeds the permitted use, you will need to obtain permission directly from the copyright holder. To view a copy of this licence, visit http://creativecommons.org/licenses/by/4.0/.

\section{References}

AIQ (2017) Biosecurity alert: tomato potato psyllid. https://www. interstatequarantine.org.au/producers/biosecurity-alert-tomat o-potato-psyllid. Accessed 17 Oct 2018

ALA (2018a) Lycium ferocissimum. https://bie.ala.org.au/species/ http://id.biodiversity.org.au/node/apni/2908311. Accessed 17 Oct 2018

ALA (2018b) Lycium australe. https://bie.ala.org.au/species/http:// id.biodiversity.org.au/node/apni/2920834. Accessed 17 Oct 2018

Alfaro-Fernández A, Siverio F, Cebrian MC, Villaescusa FJ, Font MI (2012) Candidatus Liberibacter solanacearum' associated with Bactericera trigonica-affected carrots in the canary Islands. Plant Dis 96(4):581-582

Antolinez CA, Fereres A, Moreno A (2017) Risk assessment of "CandidatusLiberibacter solanacearum transmission by the psyllids Bactericera trigonica and B. tremblayi from Apiaceae crops to potato". Sci Rep 7(45534):1-10

Antolinez CA, Moreno A, Appezzato-da-Gloria B, Fereres A (2017) Characterization of the electrical penetration graphs of the psyllid Bactericera trigonica on carrots. Entomol Exp Appl 163:127-139

Beard SS, Scott IAW (2013) A rapid method for the detection and quantification of the vector-borne bacterium "Candidatus Liberibacter solanacearum' in the tomato potato psyllid, Bactericera cockerelli'. Entomol Exp Appl 147(2):196-200

Bernardo MA, Singer MS (2017) Parasite-altered feeding behavior in insects: integrating functional and mechanistic research frontiers. J Exp Biol 220(16):2848-2857

Bonani JP, Fereres A, Garzo E, Miranda MP, Appezzato-da-Gloria B, Lopes JRS (2010) Characterization of electrical penetration graphs of the Asian citrus psyllid, Diaphorina citri, in sweet orange seedlings. Entomol Exp Appl 134:35-49

Bosque-Pérez NA, Eigenbrode SD (2011) The influence of virusinduced changes in plants on aphid vectors: insights from luteovirus pathosystems. Virus Res 159:201-205

Buchman JL, Sengoda VG, Munyaneza JE (2011) Vector transmission efficiency of Liberibacter by Bactericera cockerelli (Hemiptera: Triozidae) in Zebra Chip Potato Disease: effects of psyllid life stage and inoculation access period. J Econ Entomol 104(5):1486-1495

Butler CD, Trumble JT (2012) The potato psyllid, Bactericera cockerelli (Šulc) (Hemiptera: Triozidae): life history, relationship to plant diseases, and management strategies. Terrest Arthropod Rev 5(2):87-111

Butler CD, Walker GP, Trumble JT (2012) Feeding disruption of potato psyllid, Bactericera cockerelli, by imidacloprid as measured by electrical penetration graphs. Entomol Exp Appl $142: 247-257$

CABI (2018) Bactericera cockerelli (Tomato/Potato Psyllid). CABI Invasive Species Compendium. https://www.cabi.org/isc/datas heet/45643. Accessed 17 Oct 2018

Cen Y, Yang C, Holford P, Beattie GAC, Spooner-hart RN, Liang G, Deng X (2012) Feeding behaviour of the Asiatic citrus psyllid, Diaphorina citri, on healthy and huanglongbing-infected citrus. Entomol Exp Appl 143(1):13-22

Dohmen-Vereijssen J, Agnew N, Barnes A, Butler R, Finlay KJ, Logan D, Powell K, Puketapu A, Sandanayaka MWR, Thompson S, Valenzuela I, Yen AL (2016) Understanding the role of alternative host plants in tomato potato psyllid and Liberibacter life cycle and ecology CRC 2079-PBCRC. https://www.pbcrc .com.au/publications/pbcrc2268. Accessed 17 Oct 2018

Ebert TA, Backus EA, Shugart HJ, Rogers ME (2018) Behavioral plasticity in probing by Diaphorina citri (Hemiptera, Liviidae): ingestion from Phloem versus Xylem is influenced by leaf age and surface. J Insect Behav 31(2):119-137

Eigenbrode SD, Bosque-Pérez NA, Davis TS (2018) Insect-borne plant pathogens and their vectors: ecology, evolution, and complex interactions. Annu Rev Entomol 63:169-194

Fereres A, Moreno A (2009) Behavioural aspects influencing plant virus transmission by homopteran insects. Virus Res 141:158-168

George J, Ammar E, Hall DG Jr, RGS \& Lapointe, SL, (2018) Prolonged phloem ingestion by Diaphorina citri nymphs compared to adults is correlated with increased acquisition of citrus greening pathogen. Sci Rep 8(10352):1-11. https://doi.org/10.1038/s4159 8-018-28442-6

Gill G (2006) Tomato psyllid detected in New Zealand. Biosecurity 69:10-11

Haapalainen M (2014) Biology and epidemics of Candidatus Liberibacter species, psyllid-transmitted plant-pathogenic bacteria. Ann Appl Biol 165(2):172-198

Halbert SE, Manjunath KL (2004) Asian citrus psyllids (Sternorrhyncha: Psyllidae) and greening disease in citrus: a literature review and assessment of risk in Florida. Fla Entomolo 87(3):330-353

Han Y, Van Oers MM, Van Houte S, Ros VID (2015) Virus-induced behavioural changes in insects. In: Mehlhorn H (ed) Host manipulations by parasites and viruses, parasitology: research monographs 7. Springer International Publishing Switzerland, Cham, pp 149-174

Hansen AK, Trumble JT, Stouthamer R, Paine TD (2008) A new huanglongbing species, "Candidatus Liberibacter psyllaurous", found to infect tomato and potato, is vectored by the psyllid Bactericera cockerelli (Šulc). Appl Environ Microbiol 74(18):5862-5865

Inoue H, Ohnishi J, Ito T, Tomimura K, Miyata S, Iwanami T, Ashihara W (2009) Enhanced proliferation and efficient transmission of Candidatus Liberibacter asiaticus by adult Diaphorina citri after acquisition feeding in the nymphal stage. Ann Appl Biol 155:29-36

Killiny N, Hijaz F, Ebert TA, Rogers ME (2017) A plant bacterial pathogen manipulates its insect vector's energy metabolism. Appl Environ Microbiol 83(5):1-15

Killiny N, Jones SE (2018) Metabolic alterations in the nymphal instars of Diaphorina citri induced by Candidatus Liberibacter asiaticus, the putative pathogen of huanglongbing. PLoS ONE 13(1):1-17 
Lei H, Tjallingii WF, Lenteren JC (1997) Effect of tethering during EPG recorded probing by adults of the greenhouse whitefly. J Appl Entomol 121(1-5):211-217

Lei W, Li P, Han Y, Gong S, Yang L, Hou M (2016) EPG recordings reveal differential feeding behaviors in sogatella furcifera in response to plant virus infection and transmission success. Sci Rep 6:30240. https://doi.org/10.1038/srep30240

Liefting LW, Health P, Biosecurity MAF, Zealand N, Box PO, Bag P, Zealand N, Ward LI, Paice KL, Weir BS, Gerard RG (2008) A New "Candidatus Liberibacter" species associated with diseases of Solanaceous crops. Plant Dis 93(3):208-214

Lopes SA, Luiz FQBF, Oliveira HT, Cifuentes-Arenas JC, Raiol-Junior LL (2016) Seasonal variation of "Candidatus Liberibacter asiaticus" titers in new shoots of citrus in distinct environments. Plant Dis 101(November):583-590

Luo X, Yen AL, Powell K, Wu F, Wang Y, Zeng L, Yang Y, Cen Y (2015) Feeding behavior of Diaphorina citri (Hemiptera: Liviidae) and its acquisition of "Candidatus Liberibacter asiaticus", on huanglongbing-infected Citrus reticulata leaves of several maturity stages. Fla Entomol 98(1):189-192

Luo X, Yen AL, Powell KS, Wu F, Wang Y, Zeng L, Yang Y, Cen Y (2015) Feeding behavior of Diaphorina citri (Hemiptera: Liviidae) and its acquisition of "Candidatus Liberibacter Asiaticus", on huanglongbing-infected citrus reticulata leaves of several maturity stages. Fla Entomol 98(1):186-192

Mann ARS, Sidhu JS, Butter NS, Sohi AS, Sekhon PS (2008) Performance of Bemisia tabaci (Hemiptera: Aleyrodidae) on healthy and cotton leaf curl virus infected cotton. Fla Entomol 91(2):249-255

Martini X, Hoffmann M, Coy MR, Stelinski LL, Pelz- KS (2015) Infection of an insect vector with a bacterial plant pathogen increases its propensity for dispersal. PLoS ONE 10(6):1-16

Mas F, Vereijssen J, Suckling DM (2014) Influence of the pathogen Candidatus Liberibacter Solanacearum on tomato host plant volatiles and psyllid vector settlement. J Chem Ecol 40(11-12):1197-1202

Mauck KE, Kenney J, Chesnais Q (2019) Progress and challenges in identifying molecular mechanisms underlying host and vector manipulation by plant viruses. Curr Opin Insect Sci 33:7-18

Mauck KE, De Moraes CM, Mescher MC (2010) Deceptive chemical signals induced by a plant virus attract insect vectors to inferior hosts. Proc Natl Acad Sci 107(8):3600-3605

McLean DL, Kinsey MG (1964) A technique for electronically recording aphid feeding and salivation. Nature 202:1358-1359

Moreno-Delafuente A, Garzo E, Moreno A, Fereres A (2013) A plant virus manipulates the behavior of its whitefly vector to enhance its transmission efficiency and spread. PLoS ONE 8(4):e61543

Mustafa T, Alvarez JM, Munyaneza JE (2015) Effect of Cyantraniliprole on probing behavior of the potato psyllid (Hemiptera: Triozidae) as measured by the electrical penetration graph technique. J Econ Entomol 108(6):2529-2535

Mustafa T, Horton DR, Cooper WR, Swisher KD, Zack S, Pappu HR, Munyaneza JE (2015) Use of electrical penetration graph technology to examine Transmission of "Candidatus Liberibacter solanacearum" to potato by three haplotypes of potato psyllid (Bactericera cockerelli; Hemiptera: Triozidae). PLoS ONE 10(9):1-20

Nachappa P, Shapiro AA, Tamborindeguy C (2012) Effect of " Candidatus Liberibacter solanacearum" on fitness of its insect vector, Bactericera cockerelli (Hemiptera: Triozidae), on tomato. Phytopathology 102(1):41-46

Noble M, Rose M (2013) African boxthorn national best practice manual-managing African boxthorn (Lycium ferocissimum) in Australia. Department of Primary Industries, Parks, Water and Enviroment, Hobart

Pearson CC, Backus E, Munyaneza JE (2010) Feeding biology of the potato psyllid, Bactericera cockerelli. In: 10th annual Zebra chip reporting session., pp. 178-182.
Pearson CC, Backus EA, Shugart HJ, Joseph E, Pearson CC, Backus EA, Shugart HJ (2014) Characterization and correlation of EPG waveforms of Bactericera Cockerelli (Hemiptera: Triozidae): variability in waveform appearance in relation to applied signal. Ann Entomol Soc Am 107(3):650-666

Pelz-Stelinski KS, Brlansky RH, Ebert TA, Rogers ME (2010) Transmission parameters for Candidatus Liberibacter asiaticus by asian citrus Psyllid (Hemiptera: Psyllidae). J Econ Entomol 103(5):1531-1541

Pompon J, Quiring D, Goyer C, Giordanengo P, Pelletier Y (2011) A phloem-sap feeder mixes phloem and xylem sap to regulate osmotic potential. J Insect Physiol 57(9):1317-1322. https://doi. org/10.1016/j.jinsphys.2011.06.007

Poulin R (2010) Parasite manipulation of host behavior: an update and frequently asked questions. In: Jane Brockmann $\mathrm{H}$ (ed) Advances in the study of behavior. Elsevier Inc., Amsterdam, pp 151-186

Sackton TB (2018) 'Comparative genomics and transcriptomics of host-pathogen interactions in insects: evolutionary insights and future directions. Curr Opin Insect Sci 31:106-113

Sandanayaka MWR, Connolly PG, Withers TM (2017) Assessment of tomato potato psyllid Bactericera cockerelli (Hemiptera: Triozidae) food plant range by comparing feeding behaviour to survival of early life stages. Aust Entomol 58(2):387-394

Sandanayaka MWR, Page-Weir NEM, Fereres A (2011) Real time EPG recordings of tomato potato psyllid (Bactericera cockerelli) feeding on tomato. N Z Plant Protect 64:294

Sandanayaka WRM, Moreno A, Tooman LK, Fereres A (2014) Stylet penetration activities linked to the acquisition and inoculation of Candidatus Liberibacter solanacearum by its vector tomato potato psyllid. Entomol Exp Appl 151:170-181

Sandanayaka WRM, Tooman LK, Hewett RE (2013) The impact of post acquisition period on detection of Candidatus Liberibacter solanacearum in tomato potato psyllid. N Z Plant Protect 66:365-373

Sarria E, Cid M, Garzo E, Fereres A (2009) Excel Workbook for automatic parameter calculation of EPG data. Comput Electron Agric 67:35-42

Secor GA, Rivera VV, Abad JA, Lee IM, Clover GRG, Liefting LW, Li X, De-Boer SH (2009) Association of "Candidatus Liberibacter solanacearum" with Zebra Chip disease of potato established by graft and psyllid transmission, electron microscopy, and PCR. Plant Dis 93(6):574-583

Sengoda VG, Buchman JL, Henne DC, Pappu HR, Munyaneza JE (2013) "Candidatus Liberibacter solanacearum" titer over time in Bactericera cockerelli (Hemiptera: Triozidae) after acquisition from infected potato and tomato plants. J Econ Entomol 106(5):1964-1972

Serikawa RH, Backus EA, Rogers ME (2012) Effects of soil-applied imidacloprid on asian citrus psyllid (Hemiptera: Psyllidae) feeding behavior. J Econ Entomol 105(5):1492-1502

Serikawa RH, Backus EA, Rogers ME (2013) Probing behaviors of adult Asian Citrus Psyllid (Hemiptera: Liviidae) are not appreciably affected by soil application of field-rate Aldicarb to Citrus. Fla Entomol 96(4):1334-1342. https://doi. org/10.1653/024.096.0412

Shi X, Gao Y, Yan S, Tang X, Zhou X, Zhang D, Liu Y (2016) Aphid performance changes with plant defense mediated by Cucumber mosaic virus titer. Virol J 13(1):70. https://doi.org/10.1186/s1298 5-016-0524-4

Simon AL, Wellham PAD, Aradottir GI, Gange AC (2017) Unravelling mycorrhiza-induced wheat susceptibility to the English grain aphid Sitobion avenae. Sci Rep 7(46497):1-11. https://doi. org/10.1038/srep46497 
Stafford CA, Walker GP, Ullman DE (2011) Infection with a plant virus modifies vector feeding behavior. Proc Natl Acad Sci USA 108(23):9350-9355

Sugio A, Dubreuil G, Giron D, Simon J (2015) Plant-insect interactions under bacterial influence: ecological implications and underlying mechanisms. J Exp Bot 66(2):467-478

Tamborindeguy C, Huot O-B, Ibanez F, Levy J (2017) The influence of bacteria on multitrophic interactions among plants, psyllids, and pathogen. Insect Sci 24(6):1-14

Teulon DAJ, Workman PJ, Thomas KL (2009) Bactericera cockerelli: incursion, dispersal and current distribution on vegetable crops in New Zealand. N Z Plant Protect 62:136-144

Thébaud G, Yvon M, Alary R, Sauvion N, Labonne G (2009) Efficient Transmission of "Candidatus Phytoplasma prunorum" is delayed by eight months due to a long latency in its host-alternating vector. Phytopathology 99(3):265-273. https://doi.org/10.1094/PHYTO $-99-3-0265$

Tjallingii WF (1978) Electronic recording of penetration behaviour by aphids. Entomol Exp Appl 24:521-530

Valenzuela I, Trebicki P, Powell KS, Vereijssen J, Norng S, Yen AL (2017) Acizzia solanicola (Hemiptera: Psyllidae) probing behaviour on two Solanum spp. and implications for possible pathogen spread. PLoS ONE 12(6):1-17

Vereijssen J, Smith GR, Weintraub PG (2018) Bactericera cockerelli (Hemiptera: Triozidae) and Candidatus Liberibacter solanacearum in potatoes in New Zealand: biology, transmission, and implications for management. J Integrat Pest Manage 9(1):1-21

Vereijssen, J, Taylor, NM, Barnes, AM, Thompson, SE, Logan, DP, Butler, RC, Yen, AL \& Finlay, KJ 2015, 'First report of "Candidatus Liberibacter solanacearum" in Jerusalem cherry (Solanum pseudocapsicum) and thorn-apple (Datura stramonium) in New Zealand', New Disease Reports, vol. 32, no. 1, p. 5197

VSN International (n.d.) GenStat for Windows 18th Edition. H. Hempstead (ed)

Walker GP (2000) A beginner's guide to electronic monitoring of Homopteran probing behavior. In: Walker GP, Backus EA (eds), Principles and applications of electronic monitoring and other techniques in the study of Homopteran feeding behavior, pp. 14-40.

Wu F, Cen Y, Deng X, Chen J, Xia Y, Liang G (2015) Movement of Diaphorina citri (Hemiptera: Liviidae) adults between huanglongbing-infected and healthy citrus. Fla Entomol 98(2):410-416

Youn Y, Backus EA, Serikawa RH, Lukasz L (2011) Correlation of an electrical penetration graph waveform with walking by Asian citrus psyllid Diaphorina citri (Hemiptera: Psyllidae). Fla Entomol 94(4):1084-1087

Publisher's Note Springer Nature remains neutral with regard to jurisdictional claims in published maps and institutional affiliations. 